\title{
QTL Across Fruit Development in Red Raspberry, A Study of A Primocane $X$ Biennial Raspberry Population.
}

Julie Graham ( $\sim$ Julie.Graham@hutton.ac.uk)

James Hutton Institute

Kay Smith

The James Hutton Institute

Katrin MacKenzie

Biomathematics and Statistics Scotland

Linda Milne

The James Hutton Institute

Nikki Jennings

James Hutton Limited

Christine Anne Hackett

Bioinformatics and statistics Scotland

\section{Research article}

Keywords:

Posted Date: January 1st, 2021

DOI: https://doi.org/10.21203/rs.3.rs-137842/v1

License: (c) (i) This work is licensed under a Creative Commons Attribution 4.0 International License. Read Full License 


\section{Abstract \\ Background}

The changing climate is altering timing of key fruit ripening processes and increasing the occurrence of fruit defects. This work aimed to expand our knowledge of the genetic control of the ripening process in raspberry by examining a biennial $x$ primocane $F_{1}$ population to determine if the progeny exhibited both primocane and biennial flowering modes, which if any was dominant, and to identify QTL and genome locations associated with fruit development to understand how developmental control in this population differs from a biennial x biennial F1 population previously studied.

\section{Results}

The progeny from this biennial x primocane population exhibited primocane fruiting completing their lifecycle in a single season and also fruiting on second-year wood not removed in season one. QTL associated with rate of fruit development were identified on both primocane and fruiting canes with both parents impacting.

\section{Conclusions}

Novel QTL associated with the developmental process of primocane fruiting were identified. These in the main, differed from developmental QTL for similar developmental stages on fruiting canes (second year canes) with only one significant overlap on linkage group 6 . In general, the process of development on fruiting canes overall differed from that in a biennial $x$ biennial population, with the differences being greatest on linkage groups 3 and 6 suggesting control of development differs in the different fruiting types. Further understanding will be achieved by examining genome regions linked to QTL to allow breeding to meet climate requirements for yield stability.

\section{Background}

Environmental changes are impacting developmental processes which ultimately affect yield. Higher winter temperatures are leading to uneven bud break in raspberry and a shift in flowering time [1], also seen in other crops in response to climate changes [2-3]. The transition to flowering is regulated by multiple environmental and internal cues which affect timing, as flowering at appropriate times ensures best use of the available growing season and is therefore relevant to yield and quality.

Raspberry is a temperate species that bears short-lived woody shoots on a long-lived perennial root system bearing juvenile and mature shoots (canes) simultaneously on an individual plant. In biennial fruiting cultivars the canes have a two-year life cycle. In contrast, primocane cultivars complete the cycle of vegetative growth, flowering and fruiting in a single season. Haskell and Lewis [see 4] regarded primocane fruiting as a discrete character which could be considered characteristic of all or nearly all of a plant's canes and postulated that it was controlled by a major gene. This interpretation is not generally supported. Keep [4] found that autumn fruiting was a continuous varying character determined quantitatively by genes acting in an additive or complementary way. The growth cycle of raspberry has been described in detail by Jennings [5] who also considered perennial and biennial fruiting as a continuous response to a range of day length/temperatures. In effect primocane-fruiting genotypes are day-length and temperature neutral [5] since they initiate their flowers in long days and high temperatures in contrast to the short day and low temperatures required for main season raspberries. These climate neutral traits may become more important as seasonal fluctuations continue and become more unpredictable. In most domesticated raspberries, the axillary buds of the first-year canes remain dormant until the second year when they then produce lateral fruiting branches. In primocane raspberries, fruit are produced at the tops of one-year old branches at the end of the first season leaving only the lower part of the cane to fruit in the second season. For a review of the developmental transitions to flowering in raspberry see Graham and Simpson [6].

Photoperiod has a major role in flowering time in many plants perceived in the leaves with a signal or 'florigen' which integrates photoperiod and temperature signals and transmits the command to flower [7]. Plants keep track of the photoperiod with an endogenous clock [8-9]. The role of the clock in flowering time control in Arabidopsis was demonstrated by QTL mapping of flowering, which identified clock-related genes [10]. Activity of CONSTANS (CO) the key component in leaves of the photoperiodic pathway is controlled by the circadian clock. At the appropriate time, CO activates transcription of FLOWERING LOCUS T(FT) which moves to the shoot apical meristem where it interacts with bZIP transcription factors [11] activating floral integrator genes including SUPPRESSOR OF CONSTANS OVEREXPRESSION1 and APETALA1 thus inducing a cascade of downstream genes leading to flowering.

The vernalisation pathway also plays a key role in regulating development of cold-sensitive floral organs. In Arabidopsis a MADs box transcription factor FLOWERING LOCUS C (FLC) plays a central role in repression of flowering before vernalization [12]. FLC is upregulated by FRIGIDA (FRI) in non-vernalized plants [13]. FLC delays flowering by binding to the regulatory regions of floral activators including $F T$, SOC1 and $b Z I P F D$ [11, 14-15]. 
After vernalization FLC remains silenced under warm conditions enabling upregulation of $F T$ and SOC1. In the SAM the FT protein forms a heterodimer with FD which promotes flowering by activating APETALA 1.

In a biennial raspberry population derived from a cross between the cultivars Latham and Glen Moy (LxGM) [16], QTL were identified across five of the seven raspberry linkage groups for timing of individual developmental stages from bud break to ripe fruit and for principal coordinate scores (PCO) that summarized the developmental process. The data were subsequently re-analysed on a more marker dense genotyping-by-sequencing (GbS) map linked to genome scaffolds, which provided greater insight into the genes regulating key steps in the developmental process [17]. The range of QTL for different stages of fruit development identified genetic regions rich in genes relevant to development, flowering and the process of ripening (see Hackett et al [17] for the full list of genes identified within QTL). Briefly, across the linkage groups genes identified include a DIVIA like MYB transcription factor (WEREWOLF) on LG 2 [18], which could be controlling flowering time, as this has been shown to be a posttranscriptional regulator of FT, a key floral regulator [19]. A MADS domain transcription factor, AGAMOUS, a pollen expressed transcription factor, PTF2 and a range of other genes were also identified linked to QTL on LG 2. LG 3 had a strong effect on ripening with a broad range of significant markers identified suggesting more than one QTL was involved. FT, transport of FT (FTIP1), a gene regulating levels of FLC (EFL7) and COL9 regulating CO, FT and SOC1 were identified at 8, 56 and $94 \mathrm{cM}$ respectively on LG3. Also associated with the QTL is RiMYB known to control phenylpropanoid metabolism including anthocyanin accumulation in fruit [20-21] but also with important roles in many other aspects of plant development including trichome development, signal transduction, disease resistance and cell division (reviewed by Jin and Martin [22]). RiMADS_01 was identified on raspberry LG5 [16] as a potential candidate affecting vernalization and is close to a QTL for green fruit and fruit set identified in the 2018 study [17] as well as QTLs for a number of PCO scores that summarise the speed of ripening. RiMADS_01 is similar to SVP modulating the timing of the developmental transition to flowering phase in response to temperature. In the 2009 paper [16], in colder seasons RiMADS_01 was associated with earlier flowering. Close to RiMADS_01 is a region which included a range of genes regulating embryo development, flower development, meristem development, cell development and photoperiodism, including ALTERED MERISTEM PROGRAM 1 (AMP1), FLOWERING PROMOTING FACTOR 1 (ATFPF1) and REDUCED VERNALISATION RESPONSE (VRN1). On LG 6 the genes identified mainly had roles in embryo development during fruit set.

The 2018 study [17] also identified a range of auxin signalling and response gene homologs within the QTL including ATCUL 1, TOPLESS, NAC17, 12A, ARF6, ARF17, ATAVP1. Other genes involved in ethylene synthesis, activation and signalling were identified within multiple QTL across LG3, LG5 and LG7. Raspberry is non-climacteric, but ethylene formation may have a minor role in raspberries that may be co-ordinated with auxin and ABA formation as part of the mechanism that regulates timing of ripening in different fruit species.

The aim of this work was to expand our knowledge of the genetic control of the ripening process by examining the timing of developmental processes to ripe fruit in a biennial $x$ primocane $F_{1}$ population. We aimed to determine if the progeny exhibited both flowering modes, which if any was dominant, and to examine QTL and genome locations associated with development to gain an understanding of how control in this population differs from the biennial control previously observed in the LxGM population. Information was needed on how this population develops in terms of QTL identified and how these compared with the LxGM population previously characterised. In order to achieve more adapted varieties, we need to determine and then understand the developmental control in the different flowering types. If the $F_{1} s$ flower in spring, it would suggest that biennial flowering is recessive. However, if the $F_{1} s$ do not flower until later in the year and do not set fruit until the following year, it will reveal that biennial flowering is dominant. Other scenarios in the population may include progeny which express a 1:1, or a continuum of flowering between the two parental types. In a previous study on tetraploid blackberry, the primocane fruiting trait was recessive in the cross studied [23]; however we do not know if this is the same for red raspberry or if it will be in the case in all populations. The Castro study [23] did not examine the ripening process, only the flowering type.

\section{Methods}

\section{Population Development}

In order to identify key loci controlling development to ripe fruit, 181 full-sib $F_{1}$ individuals were generated from a cross between varieties Autumn Treasure (AT), a primocane variety bred by the East Malling raspberry breeding consortium (provided by RW Walpole Ltd propagators) with excellent architectural traits such as ability to heal cane wounds and a vigorous root system and Glen Fyne (GF) bred at the James Hutton Institute by the raspberry breeding consortium (provided from the James Hutton Institute high health facility), a biennial variety with excellent fruit quality. This segregating $F_{1}$ population (ATxGF) (developed by $\mathrm{N}$. Jennings the James Hutton Institute consortium raspberry breeder) was planted in the field in three plant plots across three randomised replicates (9 clonal plants per each of the 181 genotypes). After a season to establish, the population was phenotyped in the following two seasons. Dormant pruning of the old fruiting canes occurred in late winter/early spring, cutting out previous years' fruiting canes. 6-8 primocanes were left to see if they would also fruit the following year. The canes were tipped, wired and tied in.

\section{Phenotyping}


Both primocane $(\mathrm{P})$ and fruiting (second year) canes (F) were scored for developmental stage through the ripening season in two years (s1 and s2) after a season to allow the plants to establish using a 0-7 scale as follows:

0: Tightly closed buds

1: Closed buds swell

2: $>10 \%$ open flowers

3: $>10 \%$ immature fruit set

4: Green fruit

5: Green/red fruit

6: Red fruit

7: Over ripe fruit

Details of the scores and dates are given in Table 1. The first three scores in season one were scored as $1 / 0$ according to whether the first three stages had been reached or not (Table 1a). After that a wider range of stages were observed and all subsequent records were ordinal scores of the stage reached (Table $1 \mathrm{~b})$.

\section{Map Construction}

DNA was extracted from parents and progeny as previously described [24]. A range of SSR and SNP markers from previous studies [24-33] were tested on the population. These are presented in Supplementary Table 1 for ease of reference.

Primers to either SNPs or SSRs in genome scaffolds from the GbS Latham x Glen Moy map [17] were generated using primer 3 or KASP by Design (KBiosciences) (Supplementary Table 1\&2). SNPs from the GbS scaffolds were identified using the Glen Moy genome sequence and by mapping RNA-seq data from 22 raspberry varieties onto the draft genome sequence (JHI resource, [34]) using Bowtie2 and the individual BAM files were merged into one. SNPs were discovered using freebayes using settings

"-ploidy 2 -no-population-priors -min-alternate-count 5 -min-alternate-fraction $0.2 "$.

Poor quality SNPs were filtered using a custom Java program.

PCR products were run on the ABI 3730 capillary sequencer (Applied Biosystems, Foster City, CA, USA) using ROX500 (Applied Biosystems) as an internal size standard. Size polymorphisms were analysed using Genemapper.v5 (Applied Biosystems). SNPs were identified by sequencing, (Big Dye Terminator v3.1 Cycle Sequencing Kit, Applied Biosystems) run on ABI 3730 capillary sequencer and analysed using Sequencher v5.2.4. KASPar assays were carried out with 2xKASPar v4.0 Reagent (KBioscience) and 40 ng of template DNA. These were run and analysed on 7500 Fast Real Time System (Applied Biosystems). PCR conditions for KASPar were as follows: 2 minutes @ $20^{\circ} \mathrm{C}$ (Pre PCR read), 15 minutes @ $94{ }^{\circ} \mathrm{C}, 20$ seconds @ $94{ }^{\circ} \mathrm{C}, 1$ minute @ $62{ }^{\circ} \mathrm{C}$ (decreasing by $0.7^{\circ} \mathrm{C}$ per cycle), 10 cycles, 20 seconds @ $94{ }^{\circ} \mathrm{C}, 1$ minute @ $55{ }^{\circ} \mathrm{C}, 32 \mathrm{cycles}, 2$ minutes @ $20{ }^{\circ} \mathrm{C}$ (Post-PCR read).

\section{Linkage Analysis}

The linkage map was constructed using the JoinMap 4.1 software [35]. A total of 267 markers segregated in the population. Segregation of the markers confirmed all progeny were from true seed generated from the ATxGF cross. Any marker for which more than $20 \%$ of the population had missing scores was excluded from the analysis. Markers were clustered into separate linkage groups based on their independence LOD score and then ordered within linkage groups using JoinMap's regression analysis ordering. Markers with a poor goodness-of-fit measure when placed on the map or showing highly significant distortion from the expected segregation ratio were excluded from the analysis.

\section{Qtl Analysis}

The phenotypic data consists of repeated ordinal scores on each plot. These can be analysed separately (Table 1a) or combined into measures of overall ripening (Table 1b). Here, a principal coordinate analysis (PCO) was used to summarise the ripening profile into independent PCO scores. The similarity between plots was calculated using the city-block measure of similarity and then the first five PCO scores were calculated. This was carried out for the fruiting cane scores and primocane scores separately, and for each year separately (as the number of scoring occasions differed 
between years). Correlations between the principal coordinates and the original scores were examined to see how these were related and interpret the PCOs.

A general linear model of the individual ripening scores and the first five PCO scores from each set of measurements was used to estimate the genetic and environmental components of variance, and to predict the mean trait scores for each genotype. For some measurements preliminary analysis showed spatial variation among the rows within each replicate, and so row was also included as a factor in the linear model. The estimated genotype means for the offspring were then used as phenotypic traits for QTL mapping. A mixed model was used to estimate the generalized heritability for each trait [36]. This was calculated using GenStat 20 (GenStat for Windows 20th Edition 2019, VSN International, Hemel Hempstead, UK, GenStat.co.uk) and its VHERITABILITY procedure.

QTL mapping was carried out using the MapQTL 5 software [37]. The Kruskal-Wallis test implemented in MapQTL was used as a preliminary test to identify regions of the genome that were linked to each of the individual scores and principal coordinates, and whether the phenotype was affected by alleles from one parent or both. Interval mapping was then carried out using MapQTL. A LOD threshold for interval mapping was conducted using a permutation test of 1000 permutations of each of the PCO scores from the field and polytunnel, and then taking the mean of the $95 \%$ threshold from each trait to use as a common threshold. The permutation test was conducted for each season separately as there was more missing trait data in the second season.

\section{Results}

\section{Phenotype data}

After a season to allow the plants to establish, the plants were scored in the two following seasons and in these (and all subsequent ones recorded) Autumn Treasure (primocane) and Glen Fyne (main season) behaved as expected. Autumn Treasure fruited on the primocanes and also again on any second-year wood retained. In contrast no primocane fruit was produced on Glen Fyne; these plants only fruited on second year wood. The progeny from this cross, although showing variation in the rate at which they progressed through the developmental stages (with a number of developmental QTL identified, most of which showed significant effects from both parents), all completed their lifecycle in one season and also fruited on second-year wood not removed in season one. Thus, in this cross the primocane fruiting trait looks consistent with a single gene controlling whether primocane-type behaviour occurs, while multiple QTL control the speed of ripening in both primocanes and floricanes. Autumn Treasure therefore must be homozygous at that locus and crossing the offspring to Glen Fyne would be a good test of this hypothesis as the offspring should segregate.

By the end of season one of phenotyping, plants in 30 plots were scored as dead for fruiting canes, primocanes or (most often) both. By the end of season two of phenotyping (year 3 of planting), the number of dead plants had increased to 108 due to Phytophthora root rot in the field plots and hence less robust data was available from season two and this is reflected in the number of QTL identified.

Table 1a shows the mean and median scored for the parents in each year and the mean, median and standard deviation for the offspring, together with the generalised heritability. It also shows the percentage variance explained by each PCO score and their generalised heritability (Table $1 \mathrm{~b}$ ). The heritabilities are highest in the first year but lower in the second probably due to reduced plant numbers. The first principal coordinate (PCO1) for each set show positive correlations with all the individual measurements and can be thought of as an average rate of ripening. It explains $57 \%$ of the variation in season one fruiting canes, $43 \%$ in season one primocanes, $41 \%$ in season two fruiting canes and $55 \%$ in season two primocanes, and the generalised heritabilities are $0.84,0.88,0.72$ and 0.24 respectively. The heritabilities of the other principal coordinate scores are generally lower except for PCO2 and PCO3 for the primocane data in season one. PCO2 for this set has significant positive correlations with the later scores (October) and negative correlations with the earlier scores (July/August), so PCO2 will have largest values for genotypes that started developing slowly and then developed rapidly towards the end of the season. PCO3 for this set has significant positive correlations with the July and midAugust scores, so will have largest values for genotypes that develop rapidly. 
Table 1

a. Summary of trait data for parents and progeny

\begin{tabular}{|c|c|c|c|c|c|c|c|c|c|c|c|c|}
\hline \multirow[t]{2}{*}{ Season } & \multirow[t]{2}{*}{ Trait } & \multirow[t]{2}{*}{ Date } & \multirow[t]{2}{*}{ Description } & \multirow{2}{*}{$\begin{array}{l}\text { Treasure } \\
\text { Mean }\end{array}$} & \multirow{2}{*}{$\begin{array}{l}\text { Treasure } \\
\text { Median }\end{array}$} & \multirow{2}{*}{$\begin{array}{l}\text { Fyne } \\
\text { Mean }\end{array}$} & \multirow{2}{*}{$\begin{array}{l}\text { Fyne } \\
\text { Median }\end{array}$} & \multirow{2}{*}{$\begin{array}{l}\text { Offspring } \\
\text { Mean }\end{array}$} & \multirow{2}{*}{$\begin{array}{l}\text { Offspring } \\
\text { Median }\end{array}$} & \multirow[t]{2}{*}{ SD } & \multirow[t]{2}{*}{ Range } & \multirow[t]{2}{*}{ G_herit } \\
\hline & & & & & & & & & & & & \\
\hline \multirow[t]{14}{*}{1} & $\mathrm{~F} 1$ & 15 April & $\begin{array}{l}\text { Proportion } \\
\text { with buds }\end{array}$ & 1 & 1 & 0.2 & 0 & 0.56 & 1 & 0.497 & $0-1$ & 0.65 \\
\hline & $\mathrm{F} 2$ & 22 May & $\begin{array}{l}>10 \% \text { open } \\
\text { flowers }\end{array}$ & 1 & 1 & 0 & 0 & 0.51 & 1 & 0.5 & $0-1$ & 0.79 \\
\hline & F3 & 29 May & $\begin{array}{l}>10 \% \\
\text { immature } \\
\text { green fruit }\end{array}$ & 1 & 1 & 0 & 0 & 0.41 & 0 & 0.492 & $0-1$ & 0.67 \\
\hline & $\mathrm{F} 4$ & 9 June & Fruit stage & 4 & 4 & 2.4 & 4 & 3.75 & 4 & 1.243 & $0-5$ & 0.66 \\
\hline & F5 & 24 June & Fruit stage & 6 & 6 & 3.6 & 4 & 5.08 & 5 & 1.258 & $1-6$ & 0.77 \\
\hline & $\%$ & 3 July & $\begin{array}{l}\text { Proportion } \\
\text { with ripe } \\
\text { fruit }\end{array}$ & 60 & 50 & 7.5 & 10 & 34.60 & 30 & 24.73 & $0-80$ & 0.59 \\
\hline & $\mathrm{P} 1$ & 21 July & $\begin{array}{l}\text { Primocane } \\
\text { stage }\end{array}$ & 0.83 & 1 & 0 & 0 & 0.05 & 0 & 0.22 & $0-1$ & 0.60 \\
\hline & $\mathrm{P} 2$ & 18 August & $\begin{array}{l}\text { Primocane } \\
\text { stage }\end{array}$ & 3.83 & 4 & 0 & 0 & 1.10 & 1 & 0.922 & $0-4$ & 0.76 \\
\hline & P3 & 25 August & $\begin{array}{l}\text { Primocane } \\
\text { stage }\end{array}$ & 5.17 & 5.5 & 0 & 0 & 1.56 & 1 & 1.067 & $0-6$ & 0.78 \\
\hline & $\mathrm{P} 4$ & $\begin{array}{l}1 \\
\text { September }\end{array}$ & $\begin{array}{l}\text { Primocane } \\
\text { stage }\end{array}$ & 6 & 6 & 0 & 0 & 2.15 & 2 & 1.267 & $0-6$ & 0.80 \\
\hline & P5 & $\begin{array}{l}9 \\
\text { September }\end{array}$ & $\begin{array}{l}\text { Primocane } \\
\text { stage }\end{array}$ & 7 & 7 & 0.8 & 0 & 3.03 & 3 & 1.328 & $0-7$ & 0.76 \\
\hline & P6 & 22 Sept. & $\begin{array}{l}\text { Primocane } \\
\text { stage }\end{array}$ & 7 & 7 & 1.2 & 1 & 4.04 & 4 & 1.123 & $0-7$ & 0.76 \\
\hline & P7 & 8 October & $\begin{array}{l}\text { Primocane } \\
\text { stage }\end{array}$ & 7 & 7 & 1.6 & 1 & 5.36 & 5 & 1.447 & $1-7$ & 0.81 \\
\hline & P8 & $\begin{array}{l}15 \\
\text { October }\end{array}$ & $\begin{array}{l}\text { Primocane } \\
\text { stage }\end{array}$ & 7 & 7 & 2.4 & 3 & 6.06 & 7 & 1.268 & $1-7$ & 0.79 \\
\hline \multirow[t]{14}{*}{2} & $\mathrm{~F} 1$ & 8 May & Fruit stage & 1 & 1 & 1 & 1 & 0.77 & 1 & 0.419 & $0-1$ & 0.53 \\
\hline & $\mathrm{F} 2$ & 21 May & Fruit stage & 1 & 1 & 1.2 & 1 & 1.02 & 1 & 0.159 & $0-2$ & 0.34 \\
\hline & F3 & 2 May & Fruit stage & 1.5 & 1.5 & 1.8 & 2 & 1.34 & 1 & 0.475 & $1-2$ & 0.33 \\
\hline & $\mathrm{F} 4$ & 4 June & Fruit stage & 2 & 2 & 2 & 2 & 1.74 & 2 & 0.44 & $1-2$ & 0.51 \\
\hline & F5 & 11 June & Fruit stage & 3 & 3 & 2.8 & 3 & 2.51 & 3 & 0.559 & $1-4$ & 0.63 \\
\hline & F6 & 18 June & Fruit stage & 3.17 & 3 & 3.6 & 4 & 3.26 & 3 & 0.622 & $2-4$ & 0.56 \\
\hline & F7 & 26 June & Fruit stage & 4 & 4 & 4 & 4 & 3.82 & 4 & 0.386 & $3-4$ & 0.37 \\
\hline & F8 & 2 July & Fruit stage & 4 & 4 & 4 & 4 & 4.08 & 4 & 0.27 & $4-5$ & 0.05 \\
\hline & F9 & 16 July & Fruit stage & 5 & 5 & 5 & 5 & 4.87 & 5 & 0.337 & $4-5$ & 0.70 \\
\hline & $\mathrm{P} 1$ & 23 July & $\begin{array}{l}\text { Primocane } \\
\text { stage }\end{array}$ & 1 & 1 & 0 & 0 & 0.14 & 0 & 0.367 & $0-2$ & 0.51 \\
\hline & P2 & 30 July & $\begin{array}{l}\text { Primocane } \\
\text { stage }\end{array}$ & 2.17 & 2 & 0 & 0 & 0.65 & 0 & 0.99 & $0-3$ & 0.06 \\
\hline & P3 & 7 August & $\begin{array}{l}\text { Primocane } \\
\text { stage }\end{array}$ & 4 & 4 & 0 & 0 & 1.92 & 2 & 1.73 & $0-5$ & 0.15 \\
\hline & $\mathrm{P} 4$ & 19 August & $\begin{array}{l}\text { Primocane } \\
\text { stage }\end{array}$ & 5 & 5 & 0 & 0 & 2.67 & 4 & 1.98 & $0-5$ & 0.16 \\
\hline & P5 & 28 August & $\begin{array}{l}\text { Primocane } \\
\text { stage }\end{array}$ & 5.8 & 6 & 0 & 0 & 3.53 & 4 & 2.365 & $0-6$ & 0.22 \\
\hline
\end{tabular}


Table 1

b. Summary of PCO statistics

\begin{tabular}{|c|c|c|c|c|}
\hline Season & Fruiting Type & PCO & $\%$ variability & G_herit \\
\hline \multirow[t]{10}{*}{ Season 1} & Main & 1 & 57.0 & 0.84 \\
\hline & Main & 2 & 15.3 & 0.26 \\
\hline & Main & 3 & 9.7 & 0.23 \\
\hline & Main & 4 & 7.3 & 0.61 \\
\hline & Main & 5 & 3.6 & 0.51 \\
\hline & Primocane & 1 & 42.6 & 0.88 \\
\hline & Primocane & 2 & 14.4 & 0.73 \\
\hline & Primocane & 3 & 5.9 & 0.66 \\
\hline & Primocane & 4 & 4.1 & 0.36 \\
\hline & Primocane & 5 & 2.9 & 0.1 \\
\hline \multirow[t]{10}{*}{ Season 2} & Main & 1 & 40.8 & 0.72 \\
\hline & Main & 2 & 15.0 & 0.16 \\
\hline & Main & 3 & 10.5 & 0.16 \\
\hline & Main & 4 & 8.0 & 0.35 \\
\hline & Main & 5 & 7.4 & 0.25 \\
\hline & Primocane & 1 & 54.5 & 0.24 \\
\hline & Primocane & 2 & 13.3 & 0.15 \\
\hline & Primocane & 3 & 6.7 & 0.18 \\
\hline & Primocane & 4 & 5.0 & 0.28 \\
\hline & Primocane & 5 & 3.9 & 0.08 \\
\hline
\end{tabular}

\section{Linkage Map Construction}

A large number of markers were tested and $70 \%$ found to be monomorphic within and between parents. Those markers that were showing heterozygosity were mapped as described.

The markers clustered clearly into linkage groups. Five groups were separated by JoinMap at a LOD of 4.0 and the final group separated into two at a LOD of 5.0. The groups varied in size from 7 to 39 markers, and in length from $34.6 \mathrm{cM}$ to $107.6 \mathrm{cM}$. Summary statistics are given in Table 2. There are markers in each group that are also on the Latham x Glen Moy (LxGM) map and these were used to match the maps and orientate the linkage groups to correspond to the published Latham x Glen Moy maps [16-17, 25, 28-30, 38-42]. All groups had markers that were heterozygous in Autumn Treasure only, Glen Fyne only and in both parents. Apart from LG3 the majority of the markers that are heterozygous in both parents have three or four alleles and so identify all four offspring genotype classes, meaning that despite their low number of markers, these maps are informative regarding the offspring genotypes for QTL mapping. 
Table 2

Linkage group summary table

\begin{tabular}{|c|c|c|c|c|c|c|}
\hline \multirow[t]{2}{*}{ Linkage Group } & \multirow[t]{2}{*}{ No. Markers } & \multirow{2}{*}{$\begin{array}{l}\text { Autumn Treasure } \\
(\mathrm{ab} \times \mathrm{aa})\end{array}$} & \multirow{2}{*}{$\begin{array}{l}\text { Glen Fyne } \\
(\mathrm{aa} \times \mathrm{ab})\end{array}$} & \multicolumn{2}{|l|}{ Both } & \multirow[t]{2}{*}{ Length (cM) } \\
\hline & & & & $(a b \times c d)$ or $(a b \times a c)$ & $(a b \times a b)$ & \\
\hline 1 & 21 & 2 & 15 & 4 & 0 & 71.8 \\
\hline 2 & 32 & 11 & 10 & 7 & 4 & 104.2 \\
\hline 3 & 31 & 18 & 7 & 1 & 5 & 107.6 \\
\hline 4 & 32 & 13 & 10 & 8 & 1 & 105.8 \\
\hline 5 & 39 & 12 & 15 & 8 & 4 & 100.1 \\
\hline 6 & 34 & 8 & 9 & 13 & 4 & 82.5 \\
\hline 7 & 7 & 1 & 3 & 3 & 0 & 34.6 \\
\hline Total & 196 & 65 & 69 & 44 & 18 & 606.6 \\
\hline
\end{tabular}


Table 3

a QTL data across linkage groups with marker and genotype means season 1 .

\begin{tabular}{|c|c|c|c|c|c|c|c|c|c|c|c|}
\hline Season & Trait & LG & Position & Nearest Locus & LOD & $A C$ & $A D$ & $\mathrm{BC}$ & BD & RMS & \% Explained \\
\hline S1 & P2_s1 & 1 & 46.6 & LG4sc111b & 4.05 & 1.565 & 0.939 & 0.900 & 0.907 & 0.542 & 14.4 \\
\hline S1 & P1_s1 & 1 & 59.1 & GMsc_49424_135_Aq & 4.58 & 0.173 & 0.000 & 0.015 & 0.017 & 0.028 & 15.4 \\
\hline S1 & P_PCO2_s1 & 2 & 0.0 & GMsc1970_snp176 & 7.27 & 0.065 & 0.058 & 0.025 & -0.104 & 0.015 & 24.9 \\
\hline S1 & P_PCO3_s1 & 2 & 0.0 & GMsc1970_snp176 & 5.46 & -0.009 & 0.019 & -0.055 & 0.038 & 0.007 & 15.0 \\
\hline S1 & P_PC01_s1 & 2 & 22.7 & GMsc592_39439_snp331 & 6.48 & -0.160 & -0.022 & 0.088 & 0.126 & 0.056 & 16.8 \\
\hline S1 & P1_s1 & 2 & 27.2 & GMsc592_39439_snp188 & 4.61 & 0.168 & 0.029 & 0.002 & 0.028 & 0.030 & 11.7 \\
\hline S1 & P2_s1 & 2 & 26.7 & GMsc592_39439_snp188 & 5.43 & 1.586 & 1.181 & 0.767 & 0.898 & 0.544 & 14.1 \\
\hline S1 & P3_s1 & 2 & 26.7 & GMsc592_39439_snp188 & 5.76 & 2.191 & 1.534 & 1.198 & 1.413 & 0.706 & 15.1 \\
\hline S1 & P4_s1 & 2 & 24.7 & GMsc592_39439_snp188 & 5.02 & 2.835 & 2.206 & 1.784 & 1.835 & 1.035 & 13.4 \\
\hline S1 & P5_s1 & 2 & 22.7 & GMsc592_39439_snp331 & 4.73 & 3.664 & 3.138 & 2.665 & 2.672 & 1.094 & 12.5 \\
\hline S1 & P6_s1 & 2 & 22.7 & GMsc592_39439_snp331 & 4.87 & 4.566 & 4.128 & 3.701 & 3.759 & 0.742 & 13.0 \\
\hline S1 & P7_s1 & 2 & 18.0 & GMsc349b & 5.7 & 5.911 & 5.613 & 5.185 & 4.656 & 1.307 & 14.4 \\
\hline S1 & P8_s1 & 2 & 17.0 & GMsc349b & 5.81 & 6.471 & 6.356 & 5.876 & 5.459 & 0.988 & 14.2 \\
\hline S1 & F_PC01_s1 & 2 & 72.8 & LG2sc73b & 4.68 & -0.081 & 0.073 & 0.019 & -0.387 & 0.147 & 11.9 \\
\hline S1 & F1_s1 & 2 & 65.1 & LG2sc86c & 5.05 & 0.477 & 0.710 & 0.537 & 0.275 & 0.130 & 13.5 \\
\hline S1 & F3_s1 & 2 & 72.8 & LG2sc73b & 4.25 & 0.398 & 0.470 & 0.464 & 0.046 & 0.140 & 10.8 \\
\hline S1 & P_PCO2_s1 & 2 & 97.5 & GMsc590_cr & 5.36 & -0.109 & 0.039 & 0.046 & 0.060 & 0.015 & 22.8 \\
\hline S1 & P1_s1 & 2 & 97.5 & GMsc590_cr & 4.85 & 0.201 & 0.013 & 0.012 & 0.001 & 0.027 & 19.2 \\
\hline S1 & P_PC01_s1 & 4 & 5.3 & GMsc213_47434_MYB4 & 7.08 & -0.173 & 0.011 & 0.094 & 0.092 & 0.055 & 18.8 \\
\hline S1 & P2_s1 & 4 & 5.3 & GMsc213_47434_MYB4 & 6.36 & 1.635 & 1.058 & 0.776 & 0.914 & 0.520 & 17.9 \\
\hline S1 & P3_s1 & 4 & 5.3 & GMsc213_47434_MYB4 & 7.06 & 2.201 & 1.507 & 1.250 & 1.272 & 0.671 & 19.2 \\
\hline S1 & P4_s1 & 4 & 5.3 & GMsc213_47434_MYB4 & 6.78 & 2.920 & 1.994 & 1.825 & 1.863 & 0.978 & 18.2 \\
\hline S1 & P5_s1 & 4 & 5.3 & GMsc213_47434_MYB4 & 6.34 & 3.765 & 3.039 & 2.720 & 2.650 & 1.040 & 16.9 \\
\hline S1 & P6_s1 & 4 & 5.3 & GMsc213_47434_MYB4 & 6.36 & 4.633 & 4.072 & 3.757 & 3.713 & 0.707 & 17.1 \\
\hline S1 & P7_s1 & 4 & 5.3 & GMsc213_47434_MYB4 & 4.29 & 6.009 & 5.397 & 5.036 & 5.012 & 1.354 & 11.4 \\
\hline S1 & P8_s1 & 4 & 5.3 & GMsc213_47434_MYB4 & 4.49 & 6.586 & 6.211 & 5.751 & 5.727 & 1.018 & 11.6 \\
\hline S1 & F_PC01_s1 & 4 & 41.6 & GMsc22118_2RR & 4.51 & 0.190 & 0.025 & -0.106 & -0.240 & 0.142 & 15.2 \\
\hline S1 & F3_s1 & 4 & 46.6 & GMsc22118_2RR & 5.18 & 0.662 & 0.420 & 0.344 & 0.193 & 0.128 & 18.1 \\
\hline S1 & P2_s1 & 4 & 77.2 & FruitG7 & 5.25 & 1.662 & 0.925 & 0.967 & 0.952 & 0.540 & 14.8 \\
\hline S1 & P3_s1 & 4 & 76.4 & FruitG7 & 4.56 & 2.203 & 1.339 & 1.380 & 1.455 & 0.710 & 14.6 \\
\hline S1 & P1_s1 & 4 & 105.8 & GMsc2823_23204_y & 5.43 & 0.009 & 0.006 & 0.010 & 0.191 & 0.027 & 18.5 \\
\hline S1 & F_PC01_s1 & 5 & 2.0 & RUB289a & 4.81 & -0.197 & 0.176 & -0.130 & 0.051 & 0.146 & 12.6 \\
\hline S1 & F2_s1 & 5 & 3.0 & RUB289a & 4.85 & 0.327 & 0.701 & 0.389 & 0.613 & 0.161 & 12.4 \\
\hline S1 & F5_s1 & 5 & 35.4 & JHIRi_36325a_snp131 & 4.57 & 4.325 & 5.370 & 5.009 & 5.240 & 1.095 & 12.6 \\
\hline S1 & P1_s1 & 5 & 100.2 & GMsc14000_RR & 4.93 & 0.003 & 0.022 & 0.011 & 0.168 & 0.029 & 13.8 \\
\hline S1 & P_PC01_s1 & 6 & 51.3 & GMsc18_13610_snp113 & 6.74 & -0.014 & 0.075 & -0.188 & 0.095 & 0.055 & 18.7 \\
\hline S1 & P2_s1 & 6 & 50.3 & GMsc18_13610_snp113 & 6.19 & 0.953 & 0.957 & 1.749 & 0.863 & 0.505 & 20.3 \\
\hline S1 & P3_s1 & 6 & 50.3 & GMsc18_13610_snp113 & 6.43 & 1.563 & 1.317 & 2.256 & 1.274 & 0.675 & 18.8 \\
\hline
\end{tabular}




\begin{tabular}{|llllllllllll|}
\hline Season & Trait & LG & Position & Nearest Locus & LOD & AC & AD & BC & BD & RMS & \% Explained \\
\hline S1 & P4_s1 & 6 & 51.3 & GMsc18_13610_snp113 & 5.23 & 2.198 & 1.886 & 2.895 & 1.852 & 1.019 & 14.8 \\
\hline S1 & P5_s1 & 6 & 52.3 & GMsc18_13610_snp113 & 8.18 & 3.122 & 2.763 & 3.925 & 2.591 & 0.984 & 21.3 \\
\hline S1 & P6_s1 & 6 & 54.0 & LG6sc23b & 6.05 & 4.197 & 3.830 & 4.629 & 3.721 & 0.724 & 15.1 \\
\hline S1 & P7_s1 & 6 & 52.3 & GMsc18_13610_snp113 & 5.63 & 5.528 & 5.135 & 6.139 & 4.887 & 1.300 & 14.9 \\
\hline S1 & F_PC01_s1 & 6 & 57.3 & LG6sc18d & 9.94 & 0.125 & 0.225 & -0.042 & -0.290 & 0.126 & 24.4 \\
\hline S1 & F1_s1 & 6 & 57.3 & LG6sc18d & 6.74 & 0.654 & 0.769 & 0.531 & 0.346 & 0.124 & 17.4 \\
\hline S1 & F2_s1 & 6 & 57.3 & LG6sc18d & 5.99 & 0.621 & 0.704 & 0.515 & 0.275 & 0.156 & 15.4 \\
\hline S1 & F3_s1 & 6 & 54.2 & LG6sc23b & 10.16 & 0.599 & 0.610 & 0.369 & 0.148 & 0.117 & 25.0 \\
\hline S1 & F_PC01_s1 & 7 & 3.0 & GMsc5215_2RR & 5.85 & -0.289 & 0.122 & 0.044 & 0.088 & 0.138 & 17.4 \\
\hline S1 & F2_s1 & 7 & 3.0 & GMsc5215_2RR & 5.39 & 0.244 & 0.650 & 0.549 & 0.642 & 0.155 & 15.8 \\
\hline S1 & F3_s1 & 7 & 2.0 & GMsc5215_2RR & 4.78 & 0.190 & 0.574 & 0.476 & 0.415 & 0.135 & 14.0 \\
\hline
\end{tabular}

Table 3

b. QTL identified in season two

\begin{tabular}{|llllllllllll|}
\hline Season & Trait & LG & Position & Nearest Locus & LOD & AC & AD & BC & BD & RMS & \% Explained \\
\hline S2 & F8_s2 & 3 & 27.904 & ERUBSQ12.2C05 & 5.08 & 4.069 & 4.201 & 4.013 & 4.049 & 0.031 & 13.3 \\
\hline S2 & F1_s2 & 4 & 22.647 & GMsc2442ssr_str & 4.08 & 0.782 & 0.912 & 0.626 & 0.812 & 0.091 & 10.5 \\
\hline S2 & F3_s2 & 5 & 11.017 & LG5sc271a & 5.70 & 1.367 & 1.547 & 1.244 & 1.243 & 0.101 & 14.9 \\
\hline S2 & F1_s2 & 5 & 25.615 & Rub98d & 6.60 & 0.881 & 0.930 & 0.609 & 0.704 & 0.085 & 16.8 \\
\hline S2 & F_PC01_s2 & 5 & 26.679 & Rub98d & 5.07 & 0.058 & 0.115 & -0.162 & -0.019 & 0.063 & 15.0 \\
\hline S2 & F_PC01_s2 & 5 & 63.92 & GMsc229ssr_str & 5.24 & 0.020 & 0.129 & -0.114 & -0.093 & 0.064 & 13.3 \\
\hline S2 & F4_s2 & 5 & 63.92 & GMsc229ssr_str & 4.10 & 1.780 & 1.881 & 1.641 & 1.616 & 0.100 & 10.6 \\
\hline S2 & P_PC02_s2 & 5 & 63.92 & GMsc229ssr_str & 5.65 & -0.005 & 0.074 & -0.073 & -0.019 & 0.017 & 14.7 \\
\hline S2 & F5_s2 & 7 & 12.916 & GMsc115_cr & 4.91 & 2.238 & 2.663 & 2.626 & 2.549 & 0.175 & 14.1 \\
\hline S2 & F_PC01_s2 & 7 & 34.602 & GMsc5197ssr_cr & 4.64 & -0.196 & 0.088 & 0.069 & 0.059 & 0.060 & 18.9 \\
\hline S2 & F9_s2 & 7 & 34.602 & GMsc5197ssr_cr & 4.31 & 4.691 & 4.964 & 4.903 & 4.943 & 0.062 & 16.4 \\
\hline
\end{tabular}

On LG 2 (Fig. 1b), QTL were only identified in scoring season one. Four QTL regions were identified across the group (0, 17-27, 65-72 and 97 cM). Three regions were only associated with primocane traits. The region close to $0 \mathrm{cM}$ was associated with P_PCO2_s1 and P_PCO3_s1. The region from 17-27 cM was associated with each of the primocane developmental time points from July to October representing the progression of the whole developmental process from bud swell (stage 1) to ripe fruit (stage 6) locating here: P1_s1, P2_s1, P3_s1, P4_s1, P5_s1, P6_s1, P7_s1 and P8_s1. As shown in Table 3a, the offspring with genotype AC have the highest mean scores and so are developing most rapidly, while AD shows intermediate values, particularly for the later scoring dates. P_PC01_s1 also mapped here. The region close to 97 cM was associated with P1_s1 and P_PCO2_s1 representing bud break and early development, and again genotype AC showed faster ripening on this date. A region was identified associated with biennial fruiting traits at 65-72 cM for F_PC01_s1 (related to the early stages of bud break), F1_s1 (15 April, recording if buds were swelling) and F3_s1 (29 May, > 10\% immature fruit stage reached). Offspring with the AD genotype at the QTL showed the most rapid development while those with the BD genotype showed the slowest development. In season two no robust QTL could be identified on LG2, probably due to significantly lower plant numbers.

LG 3 (Fig. 1c) has one region at 27 cM, a fruiting cane trait (F8_s2 on 2 July) representing development at the green/red fruit development stage reached. Offspring with the AD genotype showed more rapid development than the other genotypes (Table 3b).

Five QTL were identified on LG4 (Fig. 1d), four in season one (positions 5, 41-46, 76-77, $105 \mathrm{cM}$ approx.) and another region in season two (22 cM). Around 5 cM, QTLs for eight primocane traits (P2_s1 to P8_s1 and P_PC01_s1), representing the developmental process from bud swell to ripe fruit and P_PC01_s1 representing the average rate were detected. Genotype AC showed the fastest development, with genotype AD intermediate and BC and BD the slowest (Table 3a). At 77 cM two further QTLs for primocane traits were identified (P2_s1, 18 August and P3_s1, 25 August) representing stages from first bud swell to fruit set. Again, genotype AC showed the most rapid development. At $105 \mathrm{cM}$ a further region was identified for P1_s1: for this, genotype BD showed the most rapid development. In season two a region at $22 \mathrm{cM}$ representing a QTL for the

Page 10/15 
early stage of bud swell was identified (F1_s2, 21 May), with genotype AD showing the fastest development and genotype BC having the slowest (Table 3b). At approx. 43 cM QTLs for fruiting cane traits of F_PC01_s1 and F3_s1 (29 May) were identified representing average early development to the beginning of fruit set, with genotype AC showing the fastest development and genotype BD having the slowest. No overlap between QTLs for primocane and fruiting traits was identified.

Across LG 5 (Fig. 1e), 3 main regions were identified. One region had overlapping QTL from 2-35 cM and represented main season traits (2-3 cM, $11,25-26$, and $35 \mathrm{cM})$. One represented only primocane traits $(100 \mathrm{cM})$ and one at $63 \mathrm{cM}$ had both main and primocane traits. At 2-3 cM traits F_PC01_s1 and F2_s1 (22May) were located. These represent a weighted mean of scores and stages around open flower stage.

At 11 cM a QTL for trait F3_s2 (29 May) was detected, representing developmental scores between 1-4 (bud swell - green fruit) but mainly around the open flowers stage. At 26 cM there were QTLs for F_PC01_s2 and F1_s2 (8 May) representing bud break and early development. At 35 cM F5_s1 (24th June) was located a QTL mainly representing developmental stages 4-6 (green-ripe fruit). For each of these QTLs the AD genotype shows the most rapid development (Tables 3a, 3b). At 63 cM F_PC01_s2, F4_s2 (4th June), F5_s2 (11 June) (mainly representing early stages to early fruit expansion) and a primocane trait P_PCO2_s2. Again, the AD genotype shows the most rapid development, with slower development for BC and BD. At 100 cM P1_s1 (21 July) was located representing bud break: here genotype BD showed the most rapid development.

LG 6 is particularly interesting as it has a region spanning 50-57 cM with QTLs for a number of both primocane and main season traits (Fig. 1f). These include floricane traits F_PC01_s1 and F1_s1 (15 April representing mainly the stage bud swell reached), F2_s2 (21 May, bud swell) and F3_s1 (29 May, immature green fruit) and the primocane traits P_PC01_s1 as well as P3_s1, P4_s1, P5_s1, P6_s1 and P7_s1 (from 25 August to 8 October representing stages from bud break to Green/red fruit).

The floricane plot (Fig. 2a) shows the mean score for each genotype at marker LG6sc18d at 58 cM on LG6, which has parental genotypes ab x ac. As shown in the plot, genotype bc is significantly slower to ripen than the other genotypes. This pattern is less clear in the floricanes in $\mathrm{s} 2$ (Fig. $2 \mathrm{~b}$ ), but there is a significant difference at time point $5(p<0.05)$ and time point $6(p<0.01)$ with the bc genotype having the lowest ripening scores in each case.

For the primocane scores, the most notable feature is that genotype ab is ripening significantly faster than the other genotypes (Fig. 2c). There was no significant association of this region with the primocane scores in s2. This might be due to the different dates of scoring, as in $\mathrm{s} 1$ the primocanes were scored until mid-October but in s2 the primocane scoring finished at the end of August.

LG 7 (Fig. 1g) has two regions associated with biennial fruiting, 2-12 cM had overlapping QTL for traits of F2_s1 (22 May early bud development) and F3_s1 (29 May bud swell), 12 cM with F5_s2 (11 June, fruit set) and a second region at 34 cM with F9_s2 (16 July, Green fruit) and F_PCO1_s2. For each of these the offspring with genotype AC had slower development than the other genotypes.

\section{Comparison of Treasure x Glen Fyne (ATXGF) map with Latham x Glen Moy (LxGM)}

Comparisons with the previously published ripening data from the Latham x Glen Moy (LxGM) population were possible to some extent due to common markers from genome scaffolds and other markers previously mapped. No ripening related QTL were previously identified on LG 1 on the LxGM map from the biennial cross, but as the traits identified on ATxGF map are all primocane fruiting traits this is to be expected.

The region identified here is interesting, as previous work has identified a significant QTL for crumbly fruit, a disorder in raspberry fruit development in this region on LxGM map [41]. Crumbly fruit affects both main season and primocane raspberries leading to abnormal fruit set and in main season fruiting plants is associated with the duration of the ripening period, with the longer the period the more likely the fruit will be crumbly. In the LxGM cross overlapping QTL for ripening traits and crumbly fruit are also found on LG 3. Given the nature of this cross fruiting on both primocane and second year wood this may suggest we are seeing a timing control on LG1 and we already have some knowledge of gene content to further investigate.

On LG 2 a large number of primocane traits were identified which again would not have been identified in LxGM. In terms of aligning LG2 of this map with the LxGM map, the marker ERUBLR_SQ07_4_E09 is at $100 \mathrm{cM}$ on ATxGF map and $102 \mathrm{cM}$ on LxGM. The only other markers that align are about $60 \mathrm{cM}$ away. Therefore, the two fruiting cane regions on LG2 (representing open flowers and PCO1) in this work cannot be far from the two regions around 63 (PCO1 and red fruit development) and $86 \mathrm{cM}$ (open flowers, late ripening and PCO4) on LxM LG2. In terms of the fruiting cane regions identified here that will be close to the LxGM regions we have significant information on gene content, details of which can be found in Hackett et al [17] as well as information on Gene $\mathrm{H}$ which has many effects including that on ripening [16, 43]. Genome regions in the primocane region identified in ATXGF will be examined for information to assist in understanding the role of this region as will scaffold 590 in the bottom QTL of this region and scaffold 1251 (mapped by position of ERubLRSQ07_4_E09).

On LG 3 in this study one significant region at $27 \mathrm{cM}$ was identified representing the rate of green fruit development. This is in contrast with LG3 in the LxGM main season cross which had a number of regions across this group representing many stages of development (17 cM open flowers, $62 \mathrm{cM}$ open flowers, $66 \mathrm{cM}$ \% open flowers, $76 \mathrm{cM}$ fruit set, $102 \mathrm{cM}$ fruit set, $49 \mathrm{cM}$ green fruit, $105 \mathrm{cM}$ green fruit, $9 \mathrm{cM}$ red fruit, $16 \mathrm{cM}$ PCO1, $56 \mathrm{cM}$ PC01, 94 cM PCO2, 76 cM PCO4). In terms of common markers, the closest marker to the QTL at 27 cM on ATxGF map is ERUBSQ12.2C05, which

Page 11/15 
is at $99.8 \mathrm{cM}$ on LG3 in LxGM, close to QTLs for fruit set and green fruit development. Again, a lot of the underlying gene content in this region is known. This is an interesting region due to the difference in QTL identified between the ripening process in the main season cross and this primocane $x$ main season cross suggesting a different genetic control.

In terms of comparisons with LG 4, in LxGM QTL were identified at 35-42 cM for green/red, red and PCO2. In this study the main season fruiting regions were around $22 \mathrm{cM}$ region and 41-46 cM and represent earlier stages of development and overall rate of early development and are probably in related regions though there are not enough common markers to confirm. The primocane regions are new to this study and due to the scaffold information from mapped markers we will be able to examine gene content.

In ATxGF on LG 5 QTL representing traits F_PC01_s1 and F2_s1 and F3_s2 for early development are located at the top of the linkage group and this aligns well with the top of LG5 group in LxGM, where fruit set and green fruit development map with markers RUB289a and ERubLR_SQ06_2_E01 linking this region on both maps. Another region at 26 cM with F_PC01_s2 and F1_s2 representing bud break and early development align based on marker Rub35a at $24 \mathrm{cM}$ here is at $18 \mathrm{cM}$ on LxGM map, close to QTL for PCO4 (which contrasts ripening across the early stages in mid-June early July) at 17 cM.At 63 cM F_PC01_s2, F4_s2, F5_s2 (mainly representing early stages to early fruit expansion). ERubLR_SQ19.1_A05 is at 67 cM on ATxGF and 59 cM on LxGM which on the more dense LxGM map is between QTLs at 40 and 72 cM for similar trait stages. The primocane trait at around $90 \mathrm{cM}$ is new and again has scaffold information that can be investigated.

Particularly interesting is a region on LG 6 on the ATXGF map where there is an area with large QTLs where traits for both primocane and fruiting cane overlap (large QTLs with LODs up to 10 for fruiting cane and 8.2 for primocanes). The pattern of genotype means for the most rapidly developing class is different for the two types of traits. No comparable region was identified on LxGM map though two other QTL were identified, one at the top of the LG with traits around the green fruit stage and another around $46 \mathrm{cM}$ for green/red fruit not detected in this study again suggesting a different genetic control mechanism.

LG7 has a number of QTL associated with the early stages of fruit development and on LxGM map there is a QTL for fruit set at 20 cM. However due to few markers on ATXGF it is not possible to say for certain these are identifying the same region.

\section{Discussion}

This work set out to understand whether biennial or primocane fruiting was dominant in the Autumn Treasure $x$ Glen Fyne population and to identify ripening related QTL in this population and determine how they varied from those in a main season $\mathrm{x}$ main season cross. This work showed that primocane fruiting was dominant and is compatible with the hypothesis that the primocane fruiting is controlled by a single genetic locus. We have identified a number of QTL for this fruiting type across LGs 1,2,4,5 and 6. Fruiting cane traits were identified on LG 2-7. The only highly significant overlap in the primocane and main season traits was on LG 6 where this region was highly significant. This is interesting as it is in a completely different location from the QTL previously detected in main x main season (LxGM) cross on LG 6 . The other major difference relates to LG 3 where in the LxGM cross a number of significant QTL are located. Other fruiting cane trait QTL identified across the other groups are in similar locations on both maps other than LG7 where we have no information due to few common markers.

In a previous study on a tetraploid blackberry cross [23] between primocane and main season parents, the progeny in this case segregated 154:34 main season: primocane fruiting. Here [23] the locus determining primocane/floricane was identified on LG 7 which relates to LG 1 ATxGF in this study. Unfortunately, there are no common markers to determine if the location is close to QTL in this study controlling primocane fruiting traits. In the ATxGF population the primocane fruiting is dominant unlike that in the Castro study [23]. In another raspberry study as part of an MSc programme (JA Spencer, Molecular marker analysis of primocane fruiting traits in raspberry. MSc Thesis North Carolina State University 2012, Raleigh) primocane fruiting was located on LG7, which corresponds to ATXGF LG 7 (and LG 4 of the Castro study [23]. Another study where the primocane fruiting trait segregated identified primocane fruiting on LGs 3 and 4 which relate to ATxGF groups 2 and 7 [44].

\section{Conclusion}

The range of different QTL and segregation patterns across studies suggest different loci are responsible for development in the different fruiting types in raspberry and therefore different markers will be important in breeding. Future work crossing one of the ATxGF progeny with the GF parent would allow mapping of the primocane locus in this cross for comparison.

The availability of genome sequences linked to markers in this work will allow us to explore the mechanisms involved in the control of ripening processes particularly focusing on the differences between fruiting types.

\section{Declarations}

Ethics approval

Not applicable 


\section{Consent for publication}

All authors have given their consent to publish and consent from the funder is not applicable

\section{Availability of Data}

The ripening data are available from the authors upon request.

The Moy $x$ Latham GbS data is available at the European Nucleotide Archive. The accession number for the GbS "study" is PRJEB23168. Link to study: http://www.ebi.ac.uk/ena/data/view/PRJEB23168. The raw data for the draft Moy genome has been submitted and has study accession number PRJEB23176. Link to study: http://www.ebi.ac.uk/ena/data/view/PRJEB23176.

The ATXGF population could be propagated and provided upon request.

\section{Competing Interests}

The authors declare that they have no competing interests

\section{Funding}

This work was funded through the Scottish Government Funding Programme (RESAS 2.1). The funding body had no influence on, or role in the research process.

Authorship

$\mathrm{CH}$ and JG made substantial contributions to conception and design, or acquisition of data, or analysis and interpretation of data and were involved in drafting the manuscript. KM assisted in the statistical analysis of the data. KS made significant contributions in data acquisition. LM carried out the bioinformatics work and NJ generated the ATxGF cross. All authors read and have approved the manuscript.

Acknowledgements

We acknowledge funding for this research from the Scottish Government Rural and Environment Science and Analytical Services division (RESAS). We acknowledge the $\mathrm{JHI}$ glasshouse and field teams for maintaining plant material and trials.

\section{References}

1. Graham J, Jennings N (2020) Rubus spp Cane Fruit. In: Biotechnology of fruit and nut crops, 2nd Edition Eds Litz RE, Pliego-Alfaro, Hormaza JI. 2020. Chapter 19.10:606-620. CABI.

2. Fitter AH, Fitter RSR. Rapid changes in flowering time in British plants. Science. 2002;296:1689-91.

3. Amano T, Smithers RJ, Sparke TH, Sutherland WJ. A 250-year index of first flowering dates and its response to temperature changes. Proc Royal Soc B-Biol Sci. 2010;277:2451-7.

4. Keep E. Primocane. (Autumn)-Fruiting - A review with particular reference to Progress in Breeding. J Hort Sci. 1988;63:1-18.

5. Jennings DL. Raspberries and Blackberries: Their Breeding. London: Diseases and Growth Academic Press; 1988.

6. Graham J, Simpson C. Developmental transitions to fruiting in red raspberry. In: Hytonen T, Graham J, Harrison R, editors. The Genomes of Rosaceous Berries and their Wild relatives. 2018;14: 199-212. Springer.

7. Liu L, Zhang Y, Yu H. Florigen trafficking integrates photoperiod and temperature signals in Arabidopsis. Journal of Integrative plant biology. 2020;62(9):1385-98.

8. Dodd AN, Jakobsen MK, Baker A, Telzerow A, Hou SW, Laplaze L, Barrot L, Poethig RS, Haseloff J, Webb AAR. Time of day modulates low temperature Ca2 + signals in Arabidopsis. Plant Sci. 2006;48:962-73.

9. Yakir E, Hilman D, Hassidim M, Green R. (2007) Circadian Clock Associated 1 transcript stability and the entrainment of the circadian clock in Arabidopsis. Plant Phys 2007;145:3, 925-932.

10. Brachi B, Faure N, Horton M, Flahauw E, Vazquez A, Nordborg M, Bergelson J, Cuguen J, Roux F. Linkage and association mapping of Arabidopsis thaliana flowering time in nature. PLOS Genetics. 2010;6:5 e10000940.

11. Abe M, Kobayashi Y, Yamamoto S, Daimon Y, Yamaguchi A, Ikeda Y, Ichinoki H, Notaguchi M, Goto K, Araki T. FD, a bZIP protein mediating signals from the floral pathway integrator FT at the shoot apex. Science. 2005;309:1052-6.

12. Michaels S, Amasino RM. Flowering Locus C encodes a novel MADS domain protein that acts as a repressor of flowering. Plant Cell. 1999;11:949-56.

13. Michaels S, Amasino RM. Loss of Flowering Locus $C$ activity eliminates the late-flowering phenotype of FRIGIDA and autonomous pathway mutations but not responsiveness to vernalization. Plant Cell. 2001;13:935-42.

Page $13 / 15$ 
14. Helliwell CA, Wood CC, Robertson M, Peacock WJ, Dennis ES. The Arabidopsis FLC protein interacts directly in vivo with SOC1 and FT chromatin and is part of a high molecular weight protein complex. Plant J. 2006;42(2):183-92.

15. Searle I, He YH, Turck F, Vincent C, Fornara F, Krober S, Amasino RA, Coupland G. The transcription factor FLC confers a flowering response to vernalization by repressing meristem competence and systemic signaling in Arabidopsis. Genes Dev. 2006;20:898-912.

16. Graham J, Hackett CA, Smith K, Woodhead M, Hein I, McCallum S. (2009) Mapping QTLs for developmental traits in raspberry from bud break to ripe fruit. Theor Appl Genet. 2009; 118:1143-1155.

17. Hackett C, Milne L, Smith K, Hedley P, Morris J, Simpson CG, Preedy K, Graham J. Enhancement of Glen Moy x Latham raspberry linkage map using GbS to further understand control of developmental processes leading to fruit ripening. BMC Genet. 2018;19:59.

18. McKenzie K, Williamson S, Smith K, Woodhead M, McCallum S, Graham J. Characterisation of the Gene H region in red raspberry: Exploring its role in cane morphology, disease resistance, and timing of fruit ripening. J of Hort. 2015;2:3.

19. Seo E, Yu J, Ryu KH, Lee MM, Lee I. WEREWOLF, a regulator of root hair pattern formation, controls flowering time through the regulation of $F T$ mRNA stability. Plant Phys. 2011;156:1867-1877.

20. Espley RV, Hellens RP, Putterill J, Stevenson DE, Kutty-Amma S, Allan AC. Red colouration in apple fruit is due to the activity of the MYB transcription factor, MdMYB10. Plant J. 2007;49:414-27.

21. Allan AC, Hellens RP, Laing WA. MYB transcription factors that colour fruit. Trends Plant Sci. 2008;13:99-102.

22. Jin HL, Martin C. (1999) Multifunctionality and diversity within the plant MYB-gene family Plant Mol Biol. 1999;41:577-585.

23. Castro P, Stafne ET, Clark JR, Lewers KS. Genetic mapping of the primocane fruiting and thornless traits of tetraploid blackberry Theor. Appl Genet. 2014;126:2521-32.

24. Graham J, Marshall B, Squire GR. Genetic differentiation over a spatial environmental gradient in wild Rubus idaeus populations. New Phytol. 2003;157:667-75.

25. Graham J, Smith K, MacKenzie K, Jorgensen L, Hackett CA, Powell W. The construction of a genetic linkage map of red raspberry (Rubus idaeus subsp idaeus) based on AFLPS, genomic-SSR and EST-SSR markers. Theor Appl Genet. 2004;109:740-9.

26. Stafne ET, Clark JR, Weber CA, Graham J, Lewers KS. (2005) Simple sequence repeat (SSR) markers for genetic mapping of raspberry and blackberry J Am Soc Hort Sci. 2005; 130:722-728.

27. Woodhead M, McCallum S, Smith K, Cardle L, Mazzitelli L, Graham J. J 2008 Identification, characterisation and mapping of simple sequence repeat (SSR) markers from raspberry root and bud ESTs. Mol Breed. 2008;22:555-63.

28. Woodhead M, Weir A, Smith K, McCallum S, MacKenzie K, Graham J. Functional markers for red raspberry. J Am Soc Hort Sci. 2010;135:41827.

29. Kassim A, Poette J, Paterson A, Zait D, McCallum S, Woodhead M, Smith K, Hackett C, Graham J. (2009) Environmental and seasonal influences on red raspberry anthocyanin antioxidant contents and identification of quantitative trait loci (QTL) Mol Nut Food Res. 2009; 53:625-634.

30. McCallum S, Woodhead M, Hackett CA, Kassim A, Paterson A, Graham J. 2010 Genetic and environmental effects influencing fruit colour. Theor Appl Genet. 2010;121:611-27.

31. Castillo NRF, Reed BM, Graham J, Fernandez F, Bassil NV. Microsatellite markers for raspberry and blackberry. J Am Soc Hort Sci. 2010;135(3):271-8.

32. Paterson A, Kassim A, McCallum S, Woodhead M, Smith K, Zait D, Graham J. 2013 Environmental and seasonal influences on red raspberry flavour volatiles and identification of quantitative trait loci(QTL) and candidate genes. Theor Appl Genet. 2013;126:33-48.

33. Simpson C, Cullen D, Hackett C, Smith K, Hallett P, McNicol J, Woodhead M, Graham J. (2016) Mapping and expression of genes associated with raspberry fruit ripening and softening Theor Appl Genet 2016;130(2):159-172.

34. Foster T, Bassil N, Dossett M, Worthington ML, Graham J. Genetic and genomic resources for Rubus breeding: a roadmap for the future". HORTRES. 2019;6:116.

35. Van Ooijen. JW Joinmap*4 Software for tha calculation of genetic linkage maps in experimental populations. Wageningen: Kyazma BV; 2006.

36. Cullis BR, Smith AB, Coombes NE. On the design of early generation variety trials with correlated data J Agri. Biol Environ Statistics. 2006;11:381-93.

37. Van Ooijen JW. MapQTL *5 Software for the mapping of quantitative trait loci in experimental populations. Wageningen: Kyazma BV; 2004.

38. Graham J, Smith K, Tierney I, MacKenzie K, Hackett C. Mapping gene H controlling cane pubescence in raspberry and its association with resistance to cane botyritis and spur blight, rust and cane spot. Theor Appl Genet. 2006;112:818-31.

39. Graham J, Hackett CA, Smith K, Woodhead M, MacKenzie K, Tierney I, Cooke D, Bayer M, Jennings N. Towards an understanding of the nature of resistance to Phytophthora root rot in red raspberry: is it mainly root vigour? Theor Appl Genet. 2011;123:585-601.

40. Graham J, Hackett CA, Smith K, Karley A, Mitchell C, Roberts H, O’Neill T. Genetic and environmental regulation of plant architectural traits and opportunities for pest and disease control in raspberry. Ann Appl Biol. 2014;165(3):318-28. 
41. Graham J, Smith K, McCallum S, Hedley P, Cullen D, Dolan A, Milne L, McNicol J, Hackett C. Towards an understanding of crumbly fruit in red raspberry SpringerPlus. 2015;4:223.

42. Woodhead M, Weir A, Smith K, McCallum S, Jennings N, Hackett CA, Graham J. (2013) Identification of QTLs for cane splitting in red raspberry (Rubus idaeus). Mol Breed. 2013;31:111-122.

43. Graham J, Smith K, Tierney I, MacKenzie K, Hackett C. Mapping gene H controlling cane pubescence in raspberry and its association with resistance to cane botyritis and spur blight, rust and cane spot. Theor Appl Genet. 2006;112:818-31.

44. Jibran R, Spencer J, Fernandez G, Montfort A, Mnejja M, Dzierzon H, Tahir J, Davies K, Chagne D, Foster TM. Two Loci, RiAF3 and RiAF4, Contribute to the Annual Fruiting Trait in Rubus. Frontiers in PI Sci 2019;1341.

\section{Figures}

\section{Figure 1}

Linkage Groups and QTL across LGs 1-7.
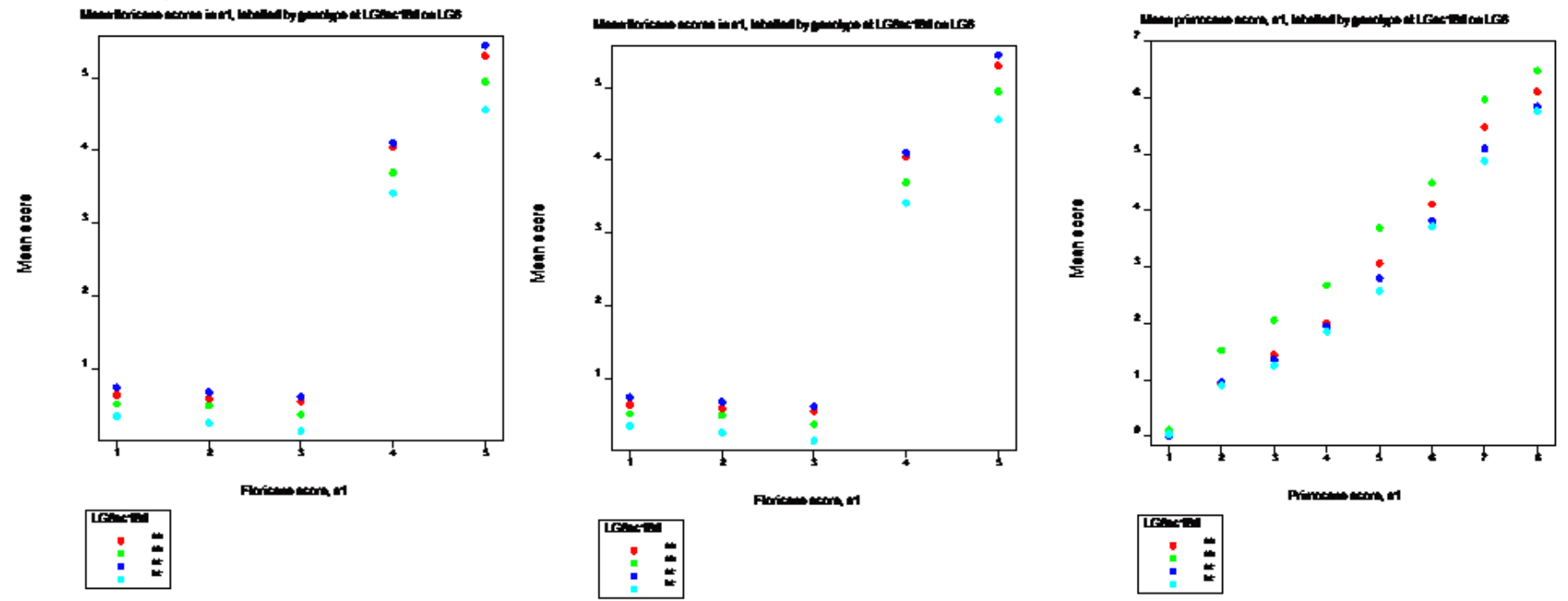

Figure 2

Plots showing rate of ripening across genotypes in floricane (season one) (a) \& season two) (b) and primocane (season one) (c). (Higher resolution images were not provided with this version)

\section{Supplementary Files}

This is a list of supplementary files associated with this preprint. Click to download.

- SupplementaryTable1SSRprimers.xIsx

- Supplementarytable2KASParmarkers.docx 